\title{
Peningkatan Prestasi Belajar Ilmu Pengetahuan Alam Materi Pencernaan dengan Menggunakan Media Model Tiga Dimensi bagi Siswa Sekolah Menengah Pertama
}

\author{
Widhiani Purwaningsih \\ SMP Negeri 1 Sawit \\ Email: widhianipurwaningsih22@gmail.com
}

\begin{abstract}
Abstrak
Tujuan dari penelitian ini adalah untuk meningkatkan prestasi belajar sains bahan pencernaan dengan menggunakan media model tiga dimensi untuk kelas VIII A SMP Negeri 1 Sawit, Boyolaliat Semester I 2018/2019 tahun akademik. Metode penelitian yang digunakan adalah Penelitian Tindakan Kelas. Variabel bebas adalah media model tiga dimensi. Prestasi belajar sains adalah variabel dependen. Populasinya adalah kelas VIII A di SMP Negeri 1 Sawitat semester pertama tahun 2018/2019 Tahun Ajaran. Cara mengambil sampel dengan nilai tes siswa dan pengawasan langsung proses pembelajaran. Berdasarkan hasil penelitian setelah penerapan pembelajaran dengan media model tiga dimensi dapat meningkat dari kondisi awal hingga siklus kedua. Ada peningkatan nilai rata-rata dari 69,84 menjadi 78,87 dan meningkat lagi menjadi 83,68, jumlah siswa selesai dari 14 menjadi 31, dari nilai terendah 40 hingga 75, meningkat 35 poin, dan skor tertinggi 85 hingga 95 , meningkat 10 poin.
\end{abstract}

\section{The Improvement of Science Learning Achievement in the Digestive Materials Using Three-Dimensional Model Media for Junior High School Student}

\author{
Widhiani Purwaningsih \\ SMP Negeri 1 Sawit \\ Email: widhianipurwaningsih22@gmail.com
}

\begin{abstract}
The purpose of this research was to improve the science learning achievement of digestive material by using three-dimensional model media for class VIII A of Junior High School 1 Sawit,Boyolaliat the First Semester of 2018/2019 academic year. The research method used is Classroom Action Research. The independent variable is a three-dimensional model media. Science learning achievement is a dependent variable. The population is class VIII A in the Junior High Schooll Sawitat the first semester 2018/2019Academic Year. How to take samples with the value of student test and direct supervision of the learning process. Research result. Based on the results of the study after the application of learning with three-dimensions model media can improve from the initial conditions to the second cycle. There was an increase in the average value of 69.84 to 78.87 and increased again to 83.68, the number of students completed from 14 to 31 , from the lowest value 40 to 75 , increased by 35 points, and the highest score of 85 to 95, increased by 10 points.
\end{abstract}

Keywords: Media model of the three-dimensions, science learning achievement. 


\section{PENDAHULUAN}

Monotonnya kegiatan Belajar Mengajar yang dilakukan oleh para guru, meskipun telah diadakannya penataran dan pelatihan melalui program MGMP, TOT, dll ternyata tidak banyak mempengaruhi guru dalam penerapannya di kelas. Hal ini dikarenakan sikap guru itu sendiri yang tidak mau berubah, media yang ada kurang memadai, dan lingkungan sekolah yang kurang mendukung.

Media Model dimensi tiga tidak memerlukan biaya yang tinggi untuk pengadaannya, diharapkan bisa menarik minat siswa untuk mempelajari materi yang diajarkan guru, karena selain penampilannya menarik anak langsung dihadapkan pada benda nyata sehingga kenangan siswa/ daya tangkap dan ingatan anak akan terpancing memperhatikan media model demensi tiga tersebut.

Menurut Ngadino (2000:38) "Media pembelajaran adalah segala sesuatu yang dapat digunakan untuk merangsang pikiran, perasaan, perhatian, dan kemauan siswa sehingga dapat mendorong terjadinya proses belajar pada diri siswa". Boediono (2004:129) menyatakan "IPA adalah hasil kegiatan manusia berupa pengetahuan, dan konsep yang terorganisasi tentang alam semesta dan kehidupannya yang diperoleh dari pengalaman melalui serangkaian proses ilmiah".

Tirtonagoro (2009: 43) menyatakan bahwa "Prestasi merupakan hasil usaha yang dilakukan dan menghasilkan perubahan yang dinyatakan dalam bentuk symbol untuk menunjukkan kemampuan dalam mencapai hasil kerja dalam waktu tertentu".

\section{METODE}

Lokasi penelitian ini berada di SMP 1 Sawit, Boyolali. Penelitian ini dilaksanakan pada semester ganjil tahun pelajaran 2018/2019 yaitu bulanAgustus 2018 sampai dengan Desember 2018. Populasi dalam penelitian ini diambil dari seluruh siswa 
kelas VIII A SMP N 1 Sawit, Boyolali semester gasal tahun pelajaran 2018/2019 yang berjumlah 31 orang.

Untuk mencapai ketuntasan belajar mata pelajaran IPA pada siswa kelas VIII A SMP N 1 Sawit, Boyolali semester Gasal tahun pelajaran2018/2019 maka dilakukan penelitian tindakan kelas dalam 2 siklus yang setiap siklus terdiri dari 4 tahapanya itu Prasiklus, Siklus I dan Siklus II

Alat pengumpul data dalam penelitian ini berupa Dokumen Nilai Siswa, Lembar dan butir soal/ unjuk kerja/ lesan. Teknik analisis data yang digunakan data observasi dan data dokumentasi

\section{HASIL DAN PEMBAHASAN}

Data Hasil Belajar Siswa pada Prasiklus (Tindakan Awal)

\begin{tabular}{|c|l|c|c|}
\hline No & \multicolumn{1}{|c|}{ Uraian } & Jumlah & Persentase (\%) \\
\hline 1 & BelumTuntas & 17 & 54.84 \\
\hline 2 & Tuntas & 14 & 45.16 \\
\hline 3 & NilaiTertinggi & 85 & \\
\hline 4 & NilaiTerendah & 40 & \\
\hline 5 & Rata-rata & 69.84 & \\
\hline
\end{tabular}

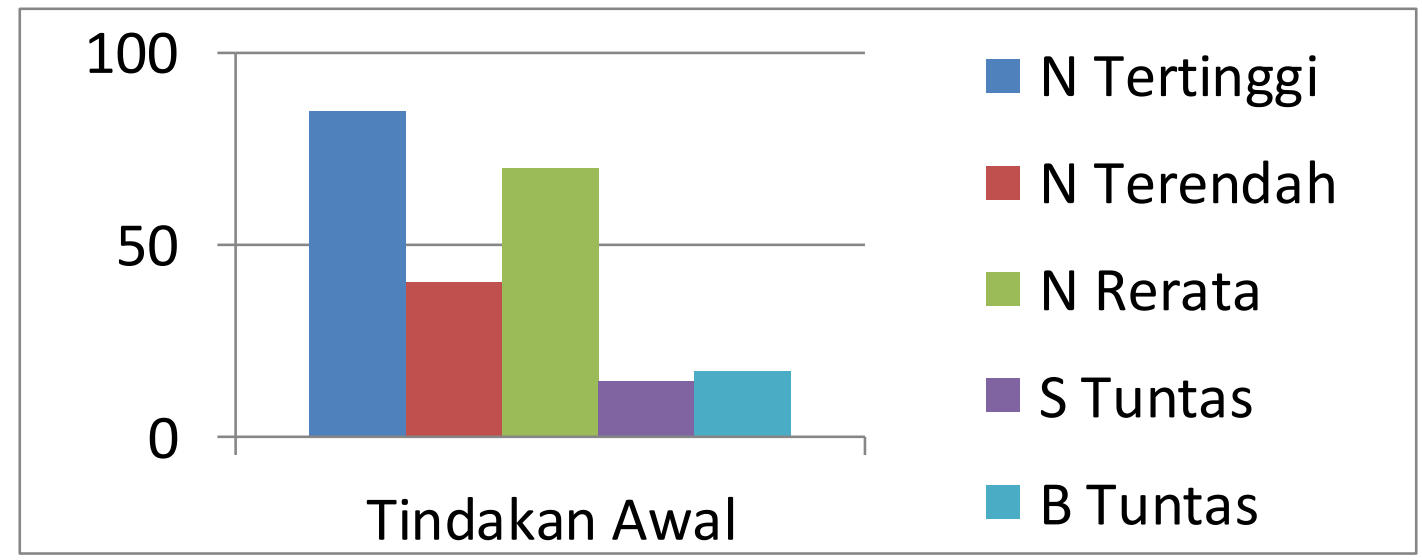

Grafik Data Hasil Belajar Siswa pada Prasiklus

Data Kondisi Proses Belajar Mengajar Prasiklus (Tindakan Awal) 


\begin{tabular}{|c|l|c|c|}
\hline No & \multicolumn{1}{|c|}{ Uraian } & Rata-rata Skor & Kriteria \\
\hline 1 & Minat belajar & 1.97 & Kurang \\
\hline 2 & Kerjasama & 2.03 & Sedang \\
\hline 3 & Inisiatif & 2.17 & Sedang \\
\hline 4 & Kreatifitas & 2.19 & Sedang \\
\hline
\end{tabular}

Data Hasil Pengamatan / Informasi Prestasi Belajar Siswa Siklus I

\begin{tabular}{|c|l|c|c|}
\hline No & \multicolumn{1}{|c|}{ Uraian } & Jumlah & Persepsi (\%) \\
\hline 1 & Tuntas & 31 & 100 \\
\hline 2 & Belum tuntas & 0 & 0 \\
\hline 3 & Nilai tertinggi & 90 & \\
\hline 4 & Nilai terendah & 75 & \\
\hline 5 & Rata-rata & 78.87 & \\
\hline
\end{tabular}

Data Hasil Pengamatan / Informasi Prestasi Belajar Siswa

Kelas VIII A Siklus II

\begin{tabular}{|c|l|c|c|}
\hline No & \multicolumn{1}{|c|}{ Uraian } & Jumlah & Persentase (\%) \\
\hline 1 & Tuntas & 31 & 100 \\
\hline 2 & Belum tuntas & 0 & 0 \\
\hline 3 & Nilai tertinggi & 95 & \\
\hline 4 & Nilai terendah & 75 & \\
\hline 5 & Rata-rata & 83,68 & \\
\hline
\end{tabular}

Peningkatan Prestasi Belajar dari Tindakan Awal, Siklus I, Siklus II

\begin{tabular}{|c|l|c|c|c|}
\hline No & \multicolumn{1}{|c|}{ Uraian } & Prasiklus & Siklus I & Siklus II \\
\hline 1 & Siswa Tuntas & 14 & 31 & 31 \\
\hline 2 & Siswa belum tuntas & 17 & 0 & 0 \\
\hline 3 & Nilai tertinggi & 85 & 90 & 95 \\
\hline 4 & Nilai terendah & 40 & 75 & 75 \\
\hline 5 & Nilai rerata & 69.84 & 78,87 & 83,68 \\
\hline
\end{tabular}




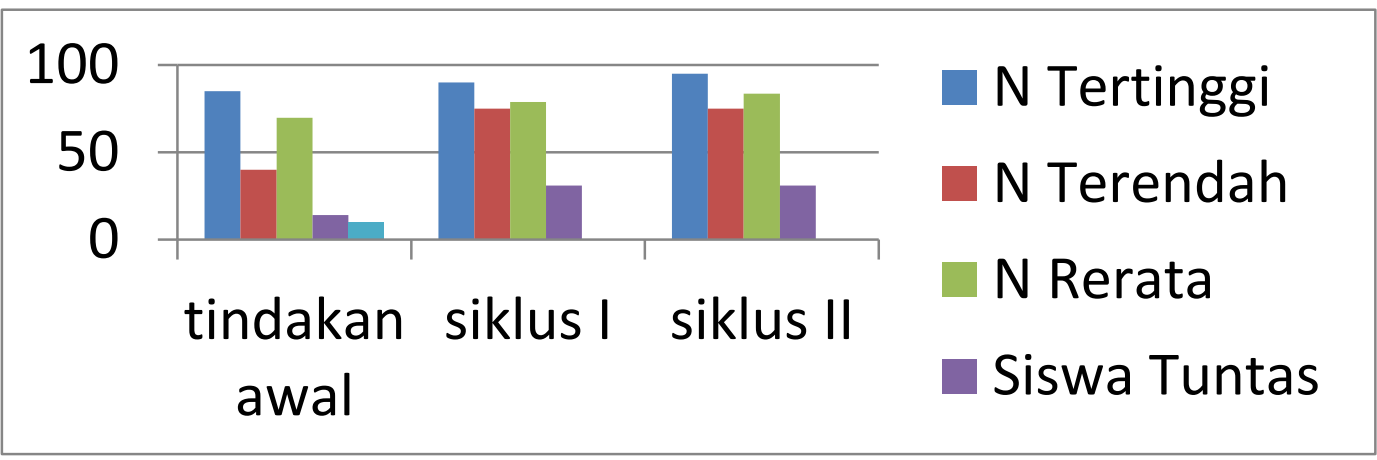

Grafik: Hasil Prestasi Prasiklus, siklus I dan siklus II

Data Hasil Pengamatan Proses Belajar Mengajar

\begin{tabular}{|c|l|c|l|c|l|c|l|}
\hline \multirow{2}{*}{ No } & \multirow{2}{*}{ Uraian } & $\begin{array}{c}\text { Rata- } \\
\text { rata } \\
\text { Skor }\end{array}$ & Kriteria & $\begin{array}{c}\text { Rata- } \\
\text { rata } \\
\text { Skor }\end{array}$ & Kriteria & $\begin{array}{c}\text { Rata- } \\
\text { rata } \\
\text { Skor }\end{array}$ & Kriteria \\
\hline 1 & Minatbelajar & 1.97 & Kurang & 3.07 & Baik & 3.22 & Baik \\
\hline 2 & Kerjasama & 2.03 & Sedang & 3.13 & Baik & 3.33 & Baik \\
\hline 3 & Tanggungjawab & 2.17 & Sedang & 3.15 & Baik & 3.34 & Baik \\
\hline 4 & Kreatifitas & 2,19 & Baik & 3.19 & Baik & 3.42 & Baik \\
\hline
\end{tabular}

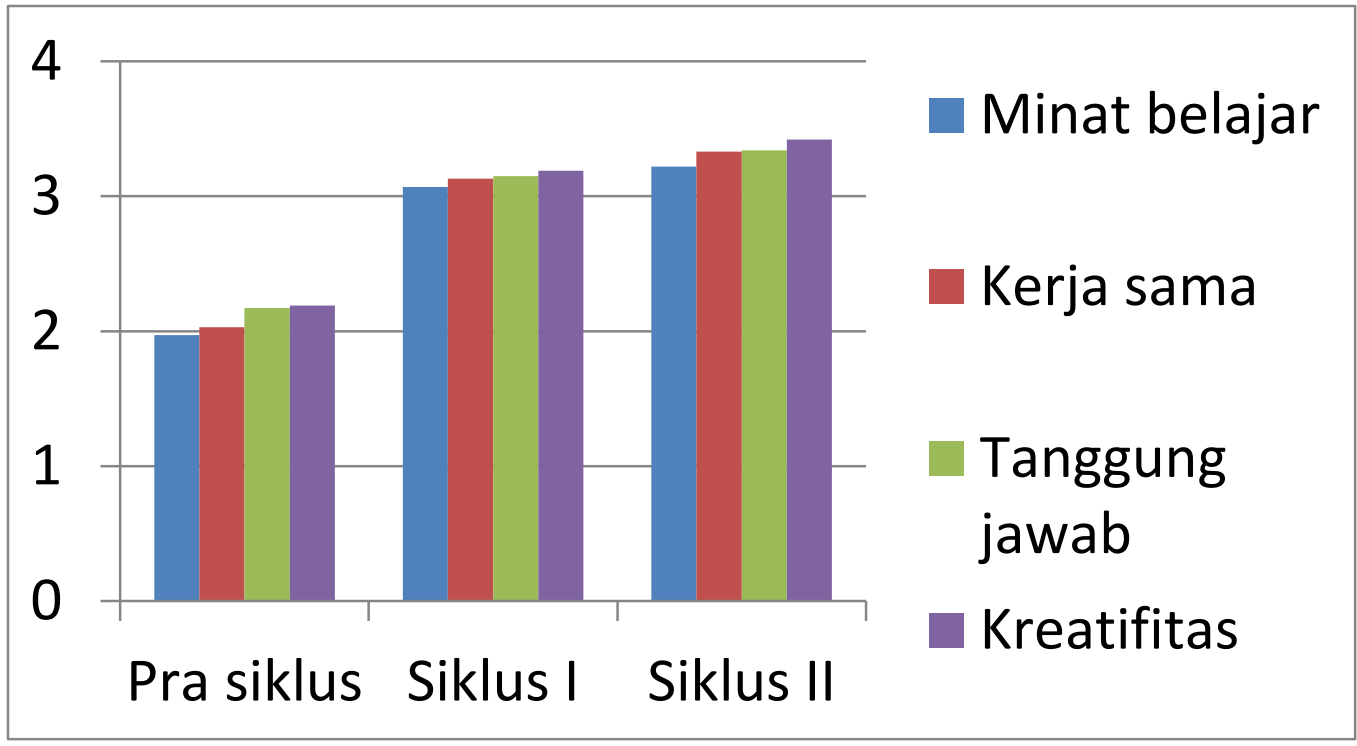

Grafik: Data Pengamatan Proses Pembelajaran 


\section{SIMPULAN DAN SARAN}

Berdasarkan pembahasan pada proses pembelajaran dan hasil belajar siswa yang dilaksanakan pada siklus I dan dilanjutkan siklus II dapat disimpulkan bahwa.

1. Dengan penggunaan media model dimensi tiga dapat meningkatkan hasil prestasi belajar IPA siswa kelas VIII A semester gasal SMP Negeri 1 Sawit tahun 2018/2019 pada materi pencernaan manusia.

a) Siswa tuntas: dari prasiklus 14siswa, meningkat menjadi 31 siswa atau $125 \%$ pada siklus I dan siklus II.

b) Siswa belum tuntas: dari prasiklus 17 siswa, menurun menjadi 0 siswa atau $125 \%$ pada siklus I dan siklus II.

c) Nilai tertinggi: dari prasiklus 85, meningkat menjadi 90, atau 3,3\% padasiklus dan meningkat lagi menjadi 95 atau 3,3\% pada siklus II.

d) Nilai terendah: dari prasiklus 40 , meningkat menjadi 75 , atau $97,36 \%$ padasiklus I dan meningkat lagi menjadi 75 atau 2,66\% pada siklus II.

e) Rata-rata nilai: dari prasiklus 69,84 meningkat menjadi 78,87 atau $14,10 \%$ pada siklus I dan meningkat lagi menjadi 83,83 atau 6,36\% pada siklus II

2. Berdasarkan proses pembelajaran setelah penerapan media model dimensi tiga dapat meningkatkan dari kondisi awal ke kondisi akhir setelah siklus I dan dilanjutkan pada siklus II terdapat peningkatan untuk:

a) Minat belajar : rata-ratanya dari prasiklus 1,97 (cukup), meningkat menjadi 3.07 (baik), atau 55,83\% pada siklus I dan meningkat lagi menjadi 3.22 (baik) atau $4,89 \%$ pada siklus II.

b) Kerjasama : rata-ratanyapadaprasiklus 2.03, meningkat menjadi 3.13 (baik) atau 54,18\% padasiklus I dan meningkat lagi menjadi 3.33 (baik), atau $6,39 \%$ pada siklus II.

c) Tanggungjawab : rata-ratanya dari prasiklus 2.17 (cukup), meningkat menjadi $3,15 \%$ (baik), atau $45,16 \%$ pada siklus I dan meningkat lagi menjadi 3.34 (baik), atau $6.03 \%$ pada siklus II. 
d) Kreativitas ; rata-ratanya dari prasiklus 2.19 (cukup), meningkat menjadi 3.19 (baik) atau 45,66\% pada siklus I dan meningkat lagi menjadi 3.42 (baik), atau 7,21\% pada siklus II.

\section{DAFTAR REFERENSI}

Ngadino (2000).Macam-macam Media Pembelajaran IPA. Yogjakarta: University Press

Arief S Sadiman (2003). Media Pembelajaran. Jakarta: University Press Mujadi (2004).Media PembelajaranDimensi 2. Jogjakarta: University Press Rochman, Natawidjaya (2007). Media Pembelajaran. Jogjakarta: Grafindo Boediono (2004).Hakekat dan Pembelajaran IPA

Prawoto (2003).Ilmu Pengetahuan Alam dan Sekitarnya. Jogjakarta Press Karso (2003).Karakteristik Ilmu PegetahuanAlam. Surabaya: University Press Sutrantinah, Tirtonegoro (2009). Belajar dan TehnikPembelajaran. Jogjakarta: University Press

W.S. Wingkel (2001). Belajar dan Pembelajaran. Surabaya: University Press Djauzali, Ahmad (2004). HakekatBelajar IPA. Jogjakarta: Multi Pressindo Sumadi, Suryabrata (2010). EvaluasiPembelajaran. Jogjakarta: University Press M Ngalim, Purwanto (2007).EvaluasiPembelajaran. Jogjakarta: Multi Pressindo Manase, Malo (2005). PenulisanKaryaIlmiah. Jogjakarta: University Press Suharsimi, Arikunto (2006). Karyallmiah. Jakarta: University Press Andreas, Proyono (2000). PenelitianTindakanKelas. Jogjakarta: University Press Syukur (2010).PenelitianTindakanKelas. Jogjakarta: University Press Sutrisno, Hadi (2002). Karyallmiah. Jakarta: University Press Fuad, Hasan (2003). EvaluasiPembelajaran. Jogjakarta: University Press 